\section{Building a safer future}

\author{
N.A. F. Smith
}

Design Paradigms: Case Histories of Error and Judgment in Engineering. By Henry Petroski. Cambridge University Press: 1994. Pp. 209. £30, \$42.95 (hbk); £12.95, \$17.95 (pbk).

HENRY Petroski's thesis is that the study of case histories is the key to understanding engineering failures and that these in turn shed light on the process of design, this being the very essence of engineering, the central feature that above all else imparts to the discipline a distinctive intel-

\section{IMAGE UNAVAILABLE FOR COPYRIGHT REASONS}

justify the study of engineering history not for its own sake but because it can monitor contemporary design or, better still, guarantee a safe future. Thus engineers, young and old, should study history for material, professional reasons.

The design problems examined by Petroski range from antiquity to modern times and each represents a paradigm of a type, such as the problem of a mistaken concept, limits to size, design change for the worse, logical errors and false success. Although it has been done before, the job is nicely done and the case for using engineering history to comprehend the nature of design is well made.

There are at least two aspects of Petroski's argument about which basic questions can be asked, however. Even when the nature of historical failures has been analysed fully and catego? rized by type, how do desigw ners at the drawing board or $\sum$ in front of a computer screen actually recognize when, or indeed if, they are up against a design paradigm of one sort or another? In short, how is hindsight turned confidently and accurately into foresight?

Second, leaving aside some Galilean examples that are of doubtful relevance anyway, the case histories discussed are drawn wholly from structural engineering and predominantly from bridgebuilding. Petroski acknowledges in the introduction that other engineering fields merit consideration, but until they are examined with comparable thoroughness, how far can we be convinced by a general philosophical position developed from only a few, specialized examples within one branch of a very large subject?

The author recommends his book for engineering students, practitioners and the general reader. The

Collapse of a church in Brousse, France (1897).

lectual and creative character. In truth it is not a new proposition, especially for civil engineering; numerous earlier writers have followed a similar approach. In fact, something of the sort has, over the years, been implicit in all manner of historical and biographical writing simply because it is natural, even essential, to scrutinize such human activities as politics, warfare or industry through the lessons of individual or corporate misjudgement or failure. To this extent, Petroski's position is neither radical nor original.

His approach also seems to be, to a degree, contrived in that it is seeking to
N. A. F. Smith is reader emeritus in the London SW7 2AZ, UK. history of technology, Imperial College,

\section{Negative synergy}

Charles Perrow

Learning from Disasters: A Management Approach. By Brian Toft and Simon Reynolds. Buttenworth-Heinemann: 1994. Pp. 140. £25, \$49.95.

THE field of risk analysis and accident prevention has grown as fast as the disaster rate in the past 15 years. One branch is technical, involving fault-tree analysis and mathematical models of probabilities and consequences; organizations, if mentioned, are assumed to be highly rational. Another branch has been far more sociological and political; organizations achieve only limited rationality, and an analysis of power and group interests is required to account for the failure to use common sense.

This book takes an interesting middle position. Accidents are sociotechnical in nature, rarely the result of technical failures, but the analysis of the sociotechnical system is determinedly 'scientific' and rational, complete with extensive taxonomies and definitions. It draws on systems theory in the social sciences, popular in the 1960s. Elaborate boxes of system components arranged in a time flow pin down errors and point to remedial actions.

The results will be disappointing to anyone who now takes it for granted that 'acts of God' are not responsible for accidents, that systems are complex, that accidents have multiple origins and that preparedness and vigilance are essential. The reader will not find much more. The elaborate taxonomies make all accidents roughly similar - they are derived from public inquiries into 19 accidents in the United Kingdom between 1965 and 1978. Furthermore, the emphasis leans toward human failures rather than failures of organizational structure. The analysis is prosaic, the writing pedantic and the recommendations heroic - put safety first, find the money to pay for it, plan ahead, communicate with every conceivable organization, be eternally vigilant, and honest when caught.

Nevertheless, there is a reasonably interesting "schematic report analysis diagram" that analyses the Cambrian Colliery accident of 1965 , based on the work of B. A. Turner (as is a great deal of the book), a pioneer in the accident field. It outlines the numerous failures and shows how the investigating committee ignored some of the more important ones. The diagram is useful for investigating committees, but when enlarged as a generic blueprint for an "organizational learning system", as it is in the final chapter, it mimics the failure of 1960 s system theory: everything is (equally) important, connected and must be taken into account. 